\title{
Effects of climate change on spatiotemporal patterns of tropical cyclone tracks and their implications for coastal agriculture in Myanmar
}

\author{
Akira Hirano $^{1}$ (D) \\ Received: 4 June 2020 / Revised: 6 January 2021 / Accepted: 22 January 2021 / Published online: 4 February 2021 \\ (c) The Author(s) 2021
}

\begin{abstract}
Important aspects for understanding the effects of climate change on tropical cyclones (TCs) are the frequency of TCs and their tracking patterns. Coastal areas are increasingly threatened by rising sea levels and associated storm surges brought on by TCs. Rice production in Myanmar relies strongly on low-lying coastal areas. This study aims to provide insights into the effects of global warming on TCs and the implications for sustainable development in vulnerable coastal areas in Myanmar. Using TC records from the International Best Track Archive for Climate Stewardship dataset during the 30-year period from 1983 to 2012, a hot spot analysis based on Getis-Ord (Gi*) statistics was conducted to identify the spatiotemporal patterns of TC tracks along the coast of Myanmar. The results revealed notable changes in some areas along the central to southern coasts during the study period. These included a considerable increase in TC tracks $(p$ value $<0.01)$ near the Ayeyarwady Delta coast, otherwise known as "the rice bowl" of the nation. This finding aligns with trends in published studies and reinforced the observed trends with spatial statistics. With the intensification of TCs due to global warming, such a significant increase in TC experiences near the major rice-producing coastal region raises concerns about future agricultural sustainability.
\end{abstract}

Keywords Tropical cyclone $\cdot$ Spatiotemporal pattern $\cdot$ Climate change $\cdot$ Myanmar $\cdot$ Coastal agriculture $\cdot$ Rice production

\section{Introduction}

People living in low-lying coastal zones and flood plains account for $50 \%$ of the Asian population and are highly vulnerable to the effects of climate change. In addition, it has been estimated that more than $90 \%$ of the global population that are exposed to tropical cyclones (TCs) live in Asia (IPCC 2014), which increases the risk these coastal communities face. TCs are powerful hydro-meteorological hazards that are frequently accompanied by strong winds, heavy rain, and storm surges that are some of the most dangerous extreme weather events on Earth (Needham et al. 2015). Due to rising sea levels, the frequency and severity of such storms have had a larger impact on low-lying and coastal zone communities. As a result of climate change, coastal areas are increasingly vulnerable to rising sea levels

Akira Hirano

akhirano@affrc.go.jp

1 Japan International Research Center for Agricultural Sciences, 1-1 Ohwashi, Tsukuba, Ibaraki 305-8686, Japan and associated storm surges (Islam et al. 2015; Al Ruheili and Radke 2020). The majority of TCs in the Bay of Bengal originate in the North Indian Ocean and their observed intensification has been noted in previous studies (Singh et al. 2000; Singh 2007; Krishna 2009; Wang et al. 2013; Balaguru et al. 2014). The majority of severe TCs in the Bay of Bengal move north- or northwestward and strike the coasts of India and Bangladesh (Singh et al. 2000; Islam and Peterson 2009).

Bangladesh is a developing country particularly affected by climate change because of the funnel-like shape of its landmass, flat topography in coastal areas, relative shallowness of the Bay of Bengal, and large population. All these factors contribute to distressing outcomes during storm surges (Dube et al. 2009). The high vulnerability of Bangladesh to TCs and storm surges was observed during Cyclone Sidr in 2007, which had an estimated death toll of 10,000 and Cyclone Aila in 2009, which rendered approximately 1 million people homeless (Islam and Chik 2011).

In contrast, Myanmar, another developing nation southeast of Bangladesh, is affected less frequently by TCs because its geographical location is less susceptible to 
possible cyclone paths (Fritz et al. 2009). However, in 2008, Cyclone Nargis (category 4 on the Saffir-Simpson scale), which displayed a peak wind speed of above $200 \mathrm{~km} / \mathrm{h}$, followed an unusual eastward track and made landfall in the Ayeyarwady Delta in Central Myanmar (Yamada et al. 2010). Myanmar's vulnerability to TCs was demonstrated when the resulting storm surge caused catastrophic damage to human lives and property with official death toll estimates exceeding 146 thousand fatalities making it the seventh deadliest cyclone ever recorded worldwide with damage estimates at over US\$ 10 billion (Fritz et al. 2009). Myanmar is a country that is highly affected by extreme weather events, and had the third-highest global climate risk index over 1997-2016 due to the overwhelming effects of this cyclone, whereas Bangladesh ranked sixth over the same time period (Eckstein et al. 2017).

Anthropogenic climate change effects on TCs must be examined in terms of their frequency and tracks (Krishna 2009). The path of Cyclone Nargis, which was characterized by an eastward movement toward Myanmar after a recurvature over the Bay of Bengal, is considered to be a rare occurrence (Yamada et al. 2010). However, Wang et al. (2013) proposed an atmospheric model consisting of observational data and numerical simulations, which can be used to predict conditions favorable for TC intensification and eastward movement toward Myanmar in future. This model revealed that the frequency and tracks of TCs will be altered by variations in the monsoon circulation induced by climate change. Moreover, a collaborative project by the Myanmar government and international organizations counting the number of historical landfalls of TCs in 1947-2008 suggested that the recurvature latitude is continually declining; therefore, TCs are more likely to hit Myanmar in future (Myanmar Government 2009). Meanwhile, Knutson et al. (2010) reviewed a variety of modeling studies and reported that there was no conclusive evidence for changes in TC tracks, indicating a high variability of modeling results. Furthermore, Walsh (2012) suggested that TC tracks, particularly in the Northern Hemisphere, where the presence of mountain ranges in mid-latitude regions interferes with numerical simulations of wind patterns, will be less predictable in future compared to its southern counterpart. In essence, the question of whether climate change has any statistical effects on tracking patterns of TCs in a given area is still debatable.

The 30-year period of 1983-2012 was reported to be the warmest period in the last 1400 year in the latest IPCC Assessment Report (IPCC 2013). Moreover, a more recent study indicated a continuing rise in temperature even after this 30-year period (Lenssen et al. 2019). As such, the hypothesis in this study is that there were some localities exhibiting increased or decreased probability of being impacted by TCs-including, but not limited to, landfalling TCs - under these unprecedented planetary conditions.
The rare recurvature pattern of Cyclone Nargis could possibly be attributed to the change in such spatial patterns. The assessment of spatiotemporal patterns of TC tracks during this period may therefore provide insights into the effects of global warming on TC tracks and their implications on sustainable development in potentially vulnerable coastal areas. In addition to the fact that this period represented a time of global warming, TC track records are expected to be more reliable compared with earlier dates (Myanmar Government 2009), making them suitable for formal statistical evaluation. This study focused on the vulnerable coastal areas of Myanmar.

The purpose of this study was, therefore, to perform a formal statistical evaluation of the changes in the spatiotemporal patterns of TC tracks under the ongoing warming trend due to climate change over a 30-year span (1983-2012). The evaluation should enable the identification of patterns, providing insights into future effects on agricultural sustainability in Myanmar. Given the economic importance of rice production and sustainable development in Myanmar, particularly in the prominent rice-producing coastal areas, it is valuable to statistically evaluate changes in the occurrence of TC tracks along the coast of Myanmar over time.

Specifically, the spatial patterns of TC tracks are examined by comparing the first 15-year (1983-1997) and the second 15-year (1998-2012) periods of the study (hereafter referred to as first interval and second interval, respectively). This is because the first interval represents a time of rapid rise in global mean surface temperature (GMST), whereas the second interval represents a time widely known as the global warming hiatus during which global warming trends declined (IPCC 2013). England et al. (2014) reported that despite observations of GMST showing an unequivocal warming over the twentieth century, the overall trend of GMST had been interrupted by periods of weak warming or even cooling; the most recent of such interruptions-the global warming hiatus - coincided with the second interval. It is generally agreed that the mechanism of the global warming hiatus was related to the cooling of the central to eastern tropical Pacific Ocean resulting in the accelerated trade winds which then lead to a substantial deceleration in surface warming through increased subsurface ocean heat uptake (England et al. 2014). Critically, the sea surface temperature (SST) is a direct measure of the energy balance that drives ocean circulation and ultimately defines the climate (Kumar et al. 2016). It is of particular interest to note that Kumar et al. (2016) reported an SST anomaly in the North Indian Ocean, which includes the region studied, herein as the SST continued to rise through the first and second intervals and the SST of the second interval was higher than that of the first interval by approximately $0.12^{\circ} \mathrm{C} / \mathrm{decade}$, while the GMST stagnated in the second interval. A similar trend was reported by Dong and McPhaden (2016) stating that the 
SST in the Bay of Bengal kept increasing over the 30-year period (1984-2013); however, the rate of increase in the second interval was significantly lower than that of the first interval in the North Indian Ocean. Contrarily, when looking at the patterns of the standardized yearly coastal SST at a local scale, the SST off the coast of most of Myanmar exhibited a unique pattern; coastal SST decreased in the first interval, then increased in the second interval (Liao et al. 2015). Overall, the region of this study was under substantially different climatic conditions between the two intervals (before and during the global warming hiatus).

\section{Materials and methods}

\section{Study area (Myanmar)}

Myanmar is the second largest country in Southeast Asia (area: 676,577 $\mathrm{km}^{2}$ ) after Indonesia (Myanmar Government 2015). The country has three primary agroecological zones (Fig. 1; Myanmar Government 2012): (i) central dry, (ii) coastal, and (iii) hilly. These zones can be further subdivided into eight physiographic regions: (i) northern hilly, (ii) central dry, (iii) Rakhine coastal, (iv) western hilly, (v) eastern hilly, (vi) Ayeyarwady Delta, (vii) Yangon Deltaic, and (viii) southern Myanmar coastal.

Agriculture forms the primary livelihood in Myanmar, with rice being a major agricultural commodity planted on approximately $50 \%$ of the cultivated area. Among the countries in the Association of Southeast Asian Nations (ASEAN), Myanmar ranks fourth in rice production (28 million tons/year; ASEAN Food Security Information System 2018). The major rice-producing physiographic regions in Myanmar are the Ayeyarwady Delta, central dry zone, Yangon Deltaic, and Rakhine coastal areas (Myanmar Government 2013). Thus, the rice production in Myanmar relies strongly on low-lying coastal regions, which are vulnerable to TC-associated risks. Therefore, any changes in the spatiotemporal patterns of TC tracks could considerably affect the sustainability of agricultural activities in these regions.

Among these physiographic regions, the Ayeyarwady Delta, known as "the rice bowl" of Myanmar, occupies an area of approximately $35,000 \mathrm{~km}^{2}$ and is home to 21 million inhabitants. The delta has a monsoonal climate, with mean annual rainfall of $1500-2000,2500$, and $3500 \mathrm{~mm}$ in its northern, southeastern, and southwestern regions, respectively. More than $90 \%$ of the rainfall occurs during the south monsoon season between mid-May and mid-November (van Driel and Nauta 2015). This region was the most affected by the storm surge caused by Cyclone Nargis in 2008. The conversion of coastal mangrove forests into agricultural land further contributed to the damage (Webb et al. 2014). The storm surge flooded approximately $7830 \mathrm{~km}^{2}$ of paddy fields and destroyed approximately $33 \%$ of the rice crop in the delta, with the majority of rice seeds stored in bamboo containers receiving damage (Stone 2009). Most rice farmers, particularly smallholders with paddy fields merely $3 \mathrm{~m}$ above the sea level, were impacted. Since Cyclone Nargis,
Fig. 1 Map of Myanmar's a agroecological and $\mathbf{b}$ physiographic zones (adapted from Myanmar Government, 2012)

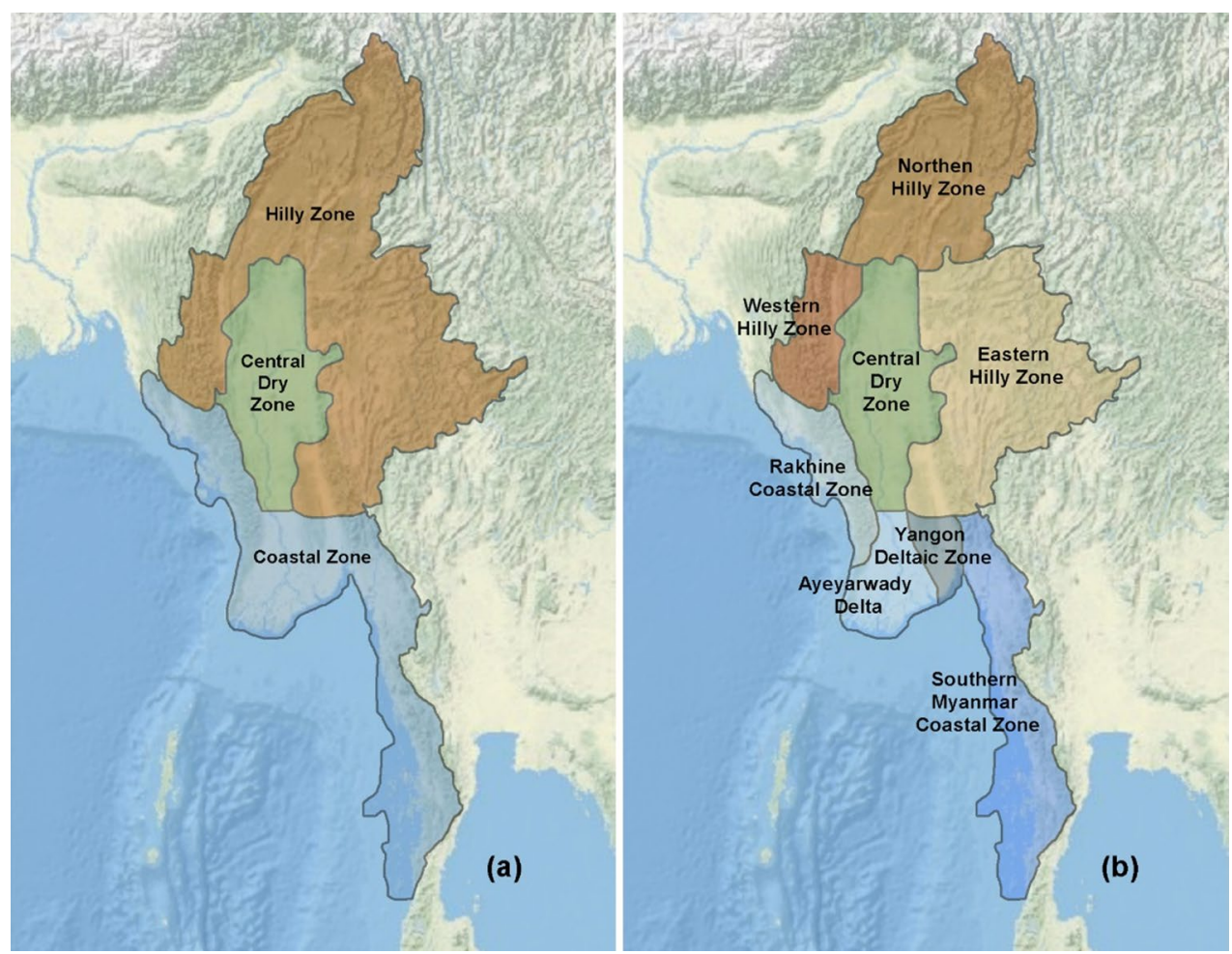


TC-generated storm surges have not been observed in this region. The main rice varieties planted across the delta include Paw San and Paw San Yin, which are local varieties that have a high market value but are not salt-tolerant and are vulnerable to TC-associated risks such as storm surges (Department of Agriculture Labutta Township 2020). Salttolerant Sin Thwe Latt and Let Yone Gyi varieties are also planted; however, they are not generally favored by local farmers as their market values are not high (May Toe Aung Myint 2020, personal communication, 7 September).

\section{Tropical cyclone track dataset}

The International Best Track Archive for Climate Stewardship (IBTrACS), which is managed by the National Oceanic and Atmospheric Administration (NOAA) in the United States of America, is one of the most comprehensive global databases of past TC tracks. In this study, IBTrACS was used for the visualization of historical cyclone tracks. The majority of the global TC datasets include quality estimates of storm positions and intensities at $6 \mathrm{~h}$ intervals; these data are termed "best track" data. In this study, the IBTrACS dataset was used as the primary input for cyclone track computations because it combines track and intensity estimates from numerous international and regional meteorological organizations and provides a centralized platform, including all factors of global climatology (for review, see Knapp et al. 2010). In this study, the latest version of IBTrACS (Knapp et al. 2018), including best track data through 2018, was used. Similar to many other global TC track datasets, the IBTrACS comprises data from 1940s onwards. However, because reliable satellite observations became available after 1976, only the data generated, thereafter, are generally considered to be suitable for the assessment of interdecadal variability due to climate change (Reynolds et al. 2002; Kossin et al. 2014).

\section{Historical tropical cyclones in the Bay of Bengal}

To depict the distribution of TCs in the Bay of Bengal, all cyclone tracks during the 30-year period of 1983-2012 recorded in the IBTrACS dataset were plotted on a regional base map (see Fig. 2). The software ESRI ${ }^{\circledR}$ ArcGIS ${ }^{\text {TM }}$ for Desktop 10.6.1 was used for visualization. As mentioned earlier, this 30-year period was chosen in this study because it was reported to represent the most prominent global warming period in history (IPCC 2013). For visual comparison, TC tracks during the first and second intervals (1983-1997 and 1998-2012, respectively) of the study period were colorcoded differently in blue and dark gray, respectively. The distinction was made because the second interval represents a period widely known as the global warming hiatus (IPCC 2013). The comparison was made to investigate potential differences in the spatial distribution of TC tracks under different climatic conditions before and during the global warming hiatus.
Fig. 2 Historical tropical cyclone (TC) tracks in the Bay of Bengal (1983-2012): the white arrow denotes the typical north- and northwestward movement of TCs. Black arrows represent directions of some TCs around the periphery of the bay

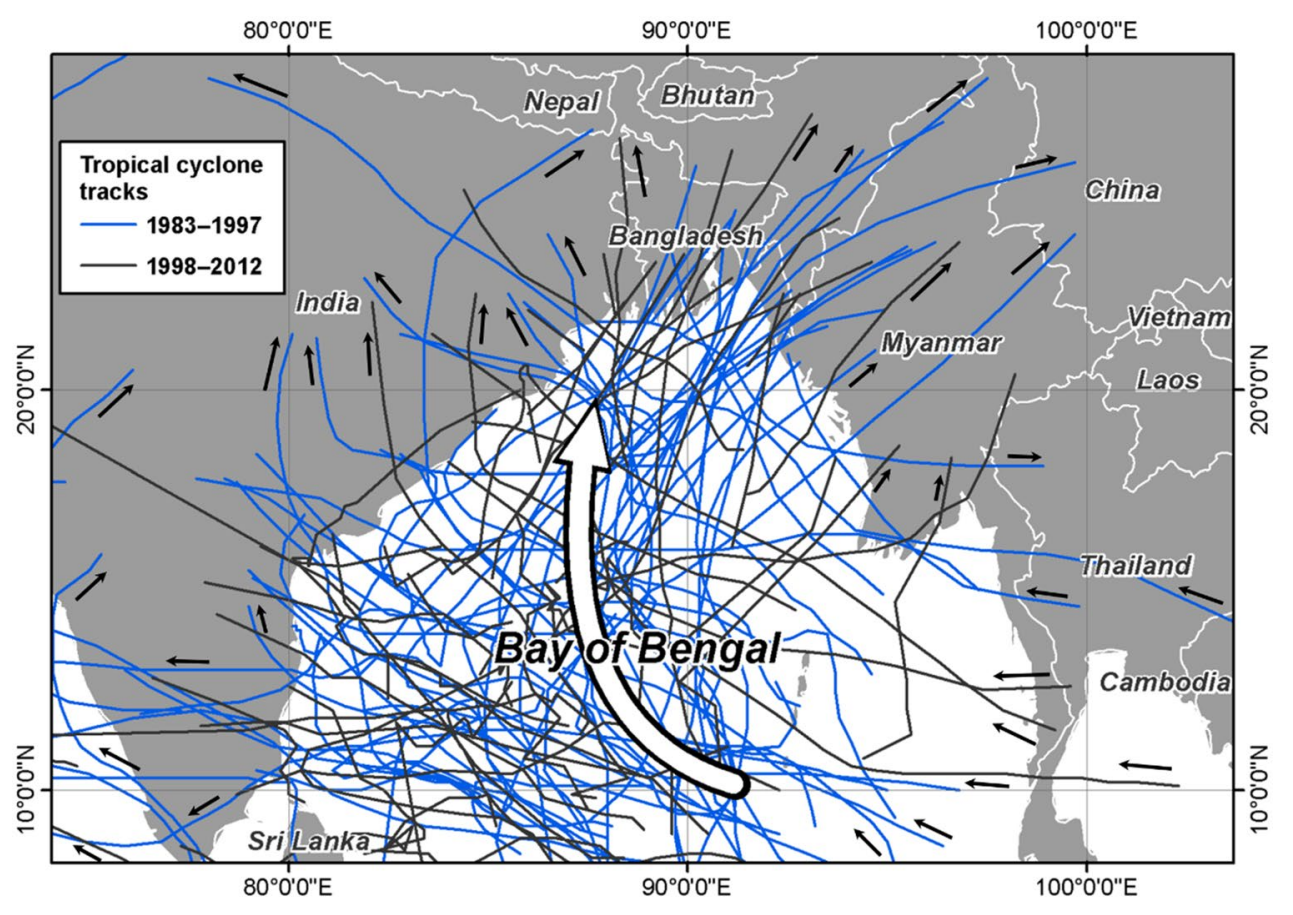




\section{Occurrence pattern for tropical cyclone tracks around Myanmar before and during the global warming hiatus}

To visually examine the occurrence pattern of TC tracks around Myanmar, the TC frequency in grid cells in the region within $9^{\circ}-29^{\circ} \mathrm{N}$ and $91^{\circ}-102^{\circ} \mathrm{E}$ was summarized at a $1^{\circ}$ resolution. This region includes Myanmar's entire territory and surrounding areas. For comparison, two maps showing the number of TCs crossing each $1^{\circ}$ grid cell for the two intervals each (1983-1997 and 1998-2012) were prepared. Again, these two intervals represent the 15 year of rapid temperature rise and the 15 year of global warming hiatus, respectively.

\section{Statistical analysis of the occurrence of tropical cyclone tracks before and during the global warming hiatus}

The visualization of the number of TCs across the area of interest was subject to the employed classification scheme. To avoid subjectivity, Gi* statistics (Getis and Ord 1992) were computed for the two time periods, facilitating the quantitative measurement and evaluation of the spatiotemporal aspects of TCs. Gi* statistics are commonly used for statistical hot spot analysis and enable the identification of hot and cold spots of a desired feature by comparing the spatial pattern of either high or low values to a spatial pattern created by a theoretically random chance. In practice, a geographic information system (GIS) calculates the statistic for the observed distribution as well as the statistic for a random distribution. The extent to which the observed distribution deviates from the random distribution represents the extent to which the pattern is more clustered or more dispersed than the random distribution. Gi* statistics measure the degree of clustering of high and low values and enable the comparison of patterns over time. Polygons with $1^{\circ}$ grid cells and corresponding data values were used as input values. These values comprised the numbers of TCs that crossed a specific grid cell during the two periods. The program ArcGIS ${ }^{\mathrm{TM}}$ was used to compute statistics ( $\mathrm{p}$ values and $\mathrm{z}$ scores) and generate color-coded maps of hot and cold spots with different confidence levels. Hot spots (in red) represent clusters of high occurrences of TC tracks, thus, indicating areas at higher risk of being impacted by TCs. Conversely, cold spots in blue represent the clusters of low occurrences of TC tracks, indicating areas at lower risk of being impacted by TCs.

\section{Results and discussion}

\section{Historical tropical cyclone tracks in the Bay of Bengal}

A total of 154 TCs were observed in the Bay of Bengal during the 30-year period of this study (1983-2012), of which 75 TCs occurred in the first interval (1983-1997) and 79 TCs in the second interval (1998-2012). Even though global warming was likely to have fueled the formation of more TCs, the number of TCs showed negligible increase across the study period. This is in agreement with the findings of Webster et al. (2005), who concluded that there was no significant change in the frequency of global tropical storms and hurricanes from 1970 to 2004, nor any significant change in TC numbers for any individual basin including the North Indian Ocean over that period. Meanwhile, the same literature indicated a substantial global increase in the number of severe TCs (Webster et al. 2005).

Most TCs that originated in the Bay of Bengal during the 30-year period (1983-2012) moved north or northwestward, and an apparent concentration of TC tracks was observed along the coasts of India and Bangladesh (Fig. 2), which were consistent with those reported by Singh et al. (2001). Based on relevant scientific literature, most damages caused by storm surges, which were the most destructive consequences of TCs, occurred on coasts along the paths of the observed TCs (Needham et al. 2015).

Qualitative analysis of TC tracks can provide a broad comparison of TC track spatial distribution between the first and second intervals. Figure 2 shows the TC tracks in the first and second intervals (blue and dark gray, respectively), of which qualitatively there are no easily noticeable differences in the spatial pattern. A strand of TC track network in the Bay of Bengal, both during the first and second intervals, exhibited an apparent concentration along the typical north and northwestward movement; most TCs landed on the Bangladeshi coastline. Further analysis indicates that the blue TC tracks (1983-1997) traveled slightly further into the continent relative to the gray TC tracks (1998-2012). This tendency may have been caused by the higher surface wind speed over the Bay of Bengal during the first interval compared to that during the second interval as reported in Kumar et al. (2016). Surface winds exhibited a weakening trend from 1990 onwards, which lowered the latent heat flux over the basin and thus contributed to the observed longterm increasing trend in SST (Kumar et al. 2016).

Compared to the Bangladeshi and northern Myanmar coastlines above $20^{\circ} \mathrm{N}$ (33 TCs), a low TC occurrence (16 TCs) was observed along coastlines south of $20^{\circ} \mathrm{N}$, accounting for most of the coastal zones in Myanmar. 


\section{Spatial distribution and occurrence of tropical cyclone tracks around Myanmar}

A visual comparison of the maps showing the number of TCs crossing each $1^{\circ}$ grid cell from 1983 to 1997 and from 1998 to 2012 revealed a decrease in TC occurrences around the border of Myanmar and Bangladesh with time (Fig. 3). Another region, approximately $700 \mathrm{~km}$ off the southern coastline of Myanmar, exhibited an abrupt decline in TC frequency. Moreover, a region in northern Thailand that exhibited a gradual decline in TC frequency in the second interval was observed, which reflects the decrease in TC tracks moving further into the continent in the second interval relative to the first interval as mentioned in the previous section. However, in general, no more than three TCs were observed throughout the study area during each 15-year interval. Thus, making an objective interpretation of significant changes in the spatial patterns only by qualitative visual inspection of the numbers of TC occurrences was difficult, which called for a formal statistical evaluation.

\section{Statistical analysis of the spatial distribution and occurrence of tropical cyclone tracks over time}

Gi* statistics with a $99 \%$ confidence interval revealed significant hot and cold spots (Fig. 4). They were used to measure patterns by comparing the actual and hypothetical random distribution of the same numbers of observed cyclones in the same area. The distribution of the hot and cold spots shares a similar pattern to that of the TC occurrences during the two intervals. However, several localities exhibited notable differences in the hot and cold spots.

The second interval exhibited a hot spot with significant increase compared to the first interval $(p$ value $<0.01)$ in the area near the Ayeyarwady Delta coast, which is located below $20^{\circ} \mathrm{N}$ latitude, changing from "not significant" to "a hot spot with 99\% confidence" (Fig. 4). Since Gi* statistics are not subjective, this change indicates an actual increase in the vulnerability to TC-derived disasters like storm surges.

The southern tip of the Myanmar coast, which is also located below $20^{\circ} \mathrm{N}$ latitude, exhibited a hot spot $(p$ value $<0.01$ ) in the second interval with the degree of TC clustering of high values changing from "not significant" to "hot spot with 99\% confidence" (Fig. 4). This also indicates increased TC tracks in the second interval. Critically, the majority of such TC tracks in this locality can be attributed to storms approaching from the east, which means that they crossed the Thai-Malay peninsula and thereby had a lower risk of storm surge induction (see the black arrows in Fig. 2).

The northern Myanmar coastal area bordering Bangladesh, which is located above $20^{\circ} \mathrm{N}$ latitude, exhibited clusters of high values at a similar confidence level ( $p$ value $<0.01$ ) (Fig. 4), indicative of no change in spatial

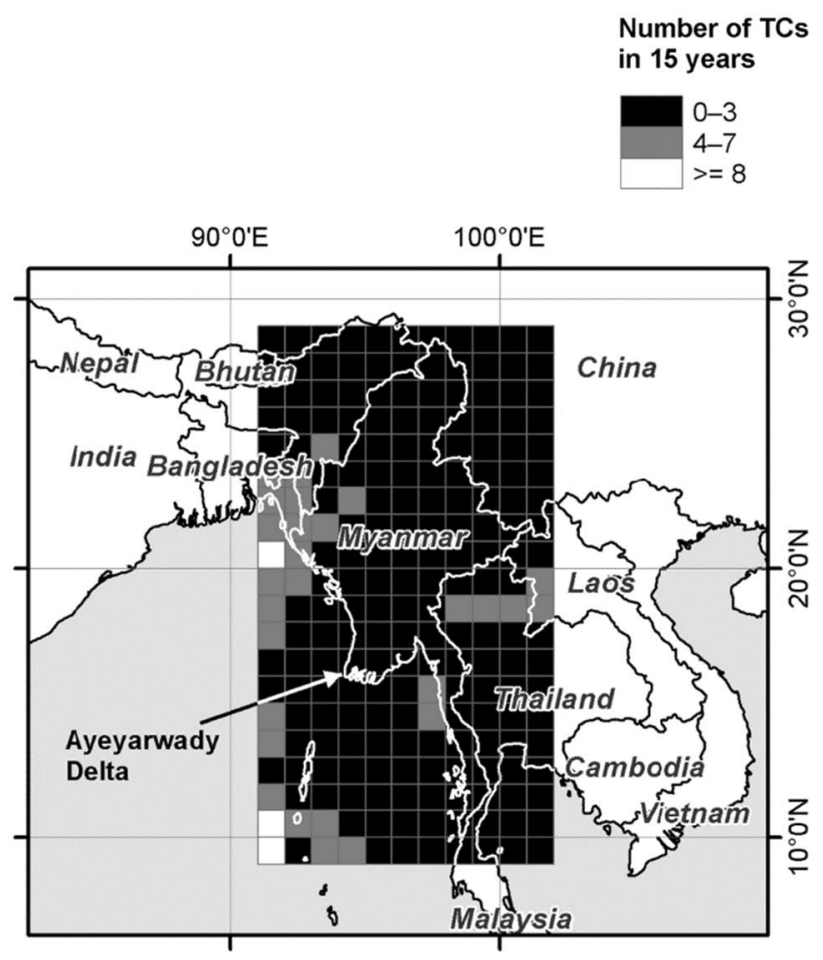

(a) 1983-1997

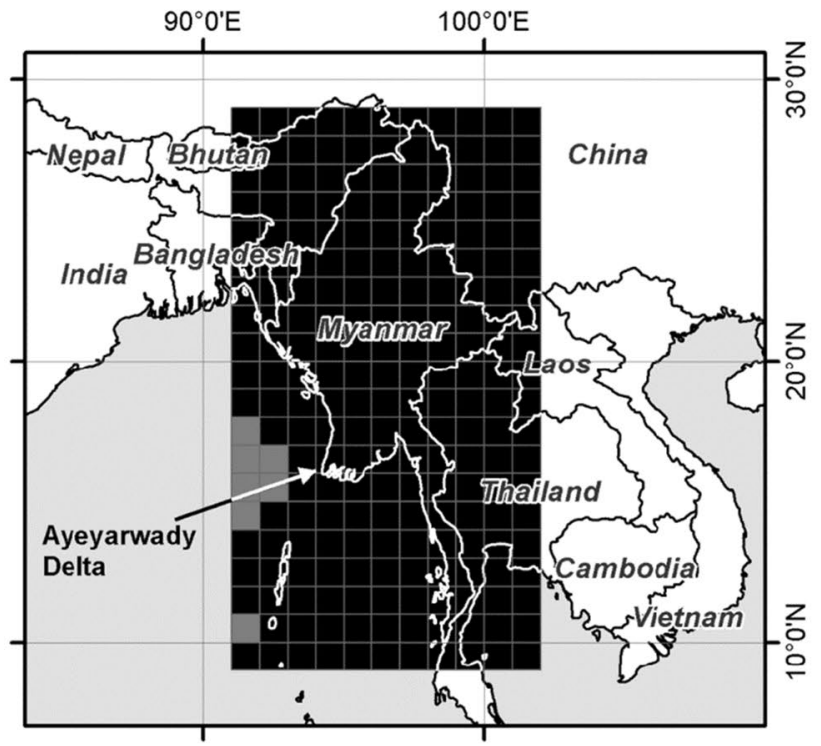

(b) 1998-2012

Fig. 3 Spatial distribution of tropical cyclone tracks at a $1^{\circ}$ resolution around Myanmar before and during the global warming hiatus: a 1983-1997 (before) and b 1998-2012 (during)

patterns between the two time intervals. Hence, the vulnerability of the northern Myanmar coastal areas to TC-associated disasters across both intervals was significantly high over the period.

The area in southern China adjacent to the northern tip of Myanmar, which is located above $20^{\circ} \mathrm{N}$ latitude, 


\section{Hot Spots/Cold Spots} based on $\mathrm{Gi}^{*}$ statistics

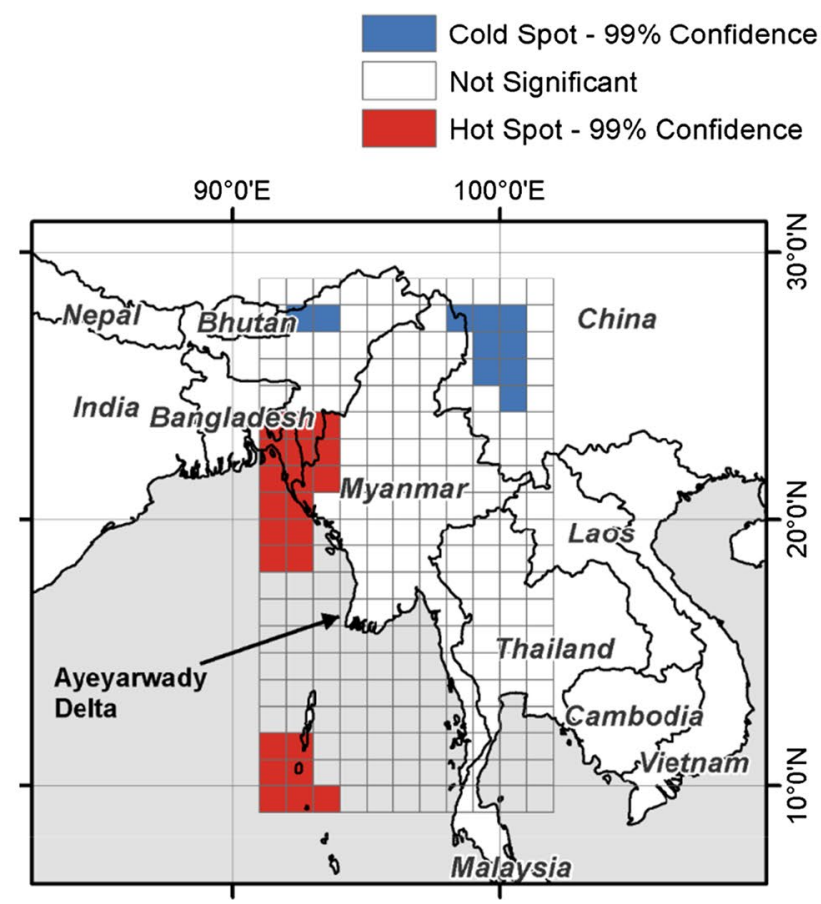

(a) 1983-1997

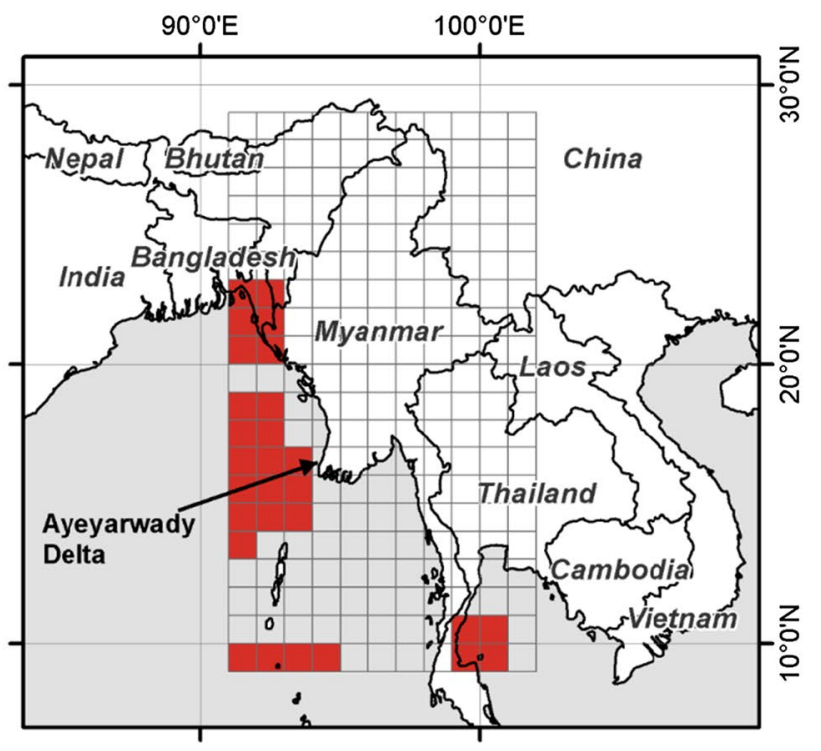

(b) 1998-2012

Fig. 4 Spatial distribution of hot and cold spots of tropical cyclone tracks at a $1^{\circ}$ resolution around Myanmar before and during the global warming hiatus: a 1983-1997 (before) and b 1998-2012 (during)

exhibited a change from "cold spot with $99 \%$ confidence" ( $p$ value $<0.01)$ to "not significant" between the two intervals (Fig. 4), which indicates a slight increase in
TC-associated risks; however, no rice-producing areas in Myanmar exist near that vicinity.

\section{Changes to likelihood of tropical cyclone impact on Myanmar coastal agriculture}

The hypothesis of this study is that there were some localities that exhibited a statistically significant increase or decrease in the probability of being impacted by TCs from the first to second interval, a time period (1983-2012) marked as the warmest 30-year period in the last 1400 year (IPCC 2013). The statistical assessment of the occurrence of TC tracks over the first and second intervals, from 1983-1997 and 1998-2012, indicates that, in general, the central to southern portion of the Myanmar coast exhibited a statistically significant increase in the probability of experiencing TCs during the second interval. Therefore, the vulnerability of agriculture to TCs and associated storm surges in this area can be regarded to have increased. Despite the stagnating GMST during the global warming hiatus (England et al. 2014), TCs increased in the second interval. This can be attributed to the regional climate trend in the Bay of Bengal characterized by the continuously increasing SST throughout the 30-year period (Kumar et al. 2016). The vulnerability of this area to TCs could increase in future because of ongoing regional warming trends and may be further exacerbate as periods of global warming hiatus punctuate future global warming trends (England et al. 2014).

Our findings suggest that the Ayeyarwady Delta is an exemplary region of where the vulnerability of rice production increases and future agricultural sustainability is at risk because of global warming induced climate change. This finding and the emergence of an extensive hot spot along the central to southern Myanmar coast (south of $20^{\circ} \mathrm{N}$ ) during the second interval reinforces findings from the Myanmar Government (2009), which indicated that TC recurvature in the Bay of Bengal decreased in latitude from 1947 to 2008.

Agriculture in Myanmar, particularly its rice production, is highly dependent on the well-being of its coastal agricultural areas. The increased probability of these coastal areas being impacted by TCs reported in this study is in agreement with the results of other studies in which various numerical storm surge models for the Bay of Bengal suggested favorable conditions for storm surge development (Jain et al. 2006; Tasnim et al. 2015). While Cyclone Nargis in 2008 was catastrophic (official death toll estimates $>146,000$; damage estimates > US $\$ 10$ billion [Fritz et al. 2009]), there have been numerous other less known TCs and storm surges that have hit coastal agricultural areas in Myanmar within the last few decades (Dube et al. 2009). With the intensification of TCs driven by global warming (Webster et al. 2005; Kossin et al. 2020), an increased probability of TCs making landfall along storm surge-prone coastal areas in Myanmar is a cause for 
concern for the food security and agricultural sustainability of Myanmar.

\section{Conclusion}

In this study, the spatiotemporal patterns of TC tracks obtained using $1^{\circ}$ grid cells during a 30 -year period (1983-2012), reportedly the warmest in history, along the Myanmar coast were statistically evaluated to provide insights into the effects of global warming on the future agricultural sustainability of Myanmar, particularly along the major coastal rice-producing areas. A hot spot analysis based on $\mathrm{Gi}^{*}$ statistics on the distribution of TC tracks comparing the first and second 15-year intervals revealed a notable increase in TC experiences near the Ayeyarwady Delta coast, otherwise known as "the rice bowl" of Myanmar. This indicates that future rice production in the country is at high risk to TCs. Although Myanmar is generally located in latitude zones that are associated with a lower probability of TCs in comparison with its neighbor Bangladesh, the statistically significant increase in TC tracks close to its major rice-producing coastal region because of climate change raises concerns about the future agricultural sustainability. Other regions experiencing an increased probability of being impacted by TCs included the southern tip of Myanmar coast ("not significant" to "hot spot with 99\% confidence") and the area in southern China ("cold spot with $99 \%$ confidence" to "not significant"), both of which had little impact on rice production because of their geographical locations. Northern Myanmar coastal areas adjacent to Bangladesh had continually exhibited high probability of high cluster of TCs during the 30-year period, signifying constant exposure to TC-associated risks.

This study indicated that there has been an intensification of TCs in the Bay of Bengal, which reflects the global intensification of TCs due to global warming (Kossin et al. 2020). Any change in the occurrence of specific TC tracks along the major rice-producing areas, as reported here, can endanger the food security and livelihoods of Myanmar's people in future. This warrants not only strengthening embankment infrastructure against future TC-induced storm surges, but also enhancing climate-smart agriculture- the ability to link social protection management and information systems with climate-related early warning systems to promote timely and flexible responses in case of severe weather events like TCs (FAO 2019).

This study aimed to capture the spatiotemporal patterns of TCs. Wind speed is a critical aspect for understanding the intensity of TCs but was excluded in this study. Since most agricultural damage caused by TCs is directly proportional to wind speed in TC-impacted areas, a study considering wind speed should be conducted for a more realistic assessment of TC-associated risk in each area. In addition, a study overlaying the distribution of TCs over agriculturally and economically important areas would also be relevant.

Acknowledgements This work was part of the "Designing weather index insurance of agricultural products to extreme events" project, a subtheme of the "Climate change measures in agricultural systems" research project (2016-2020) undertaken by the Japan International Research Center for Agricultural Sciences. I would like to express my sincere gratitude to the late Ms. Sachiko Hasegawa, the technical assistant of the project, for preparing some of the geographic information system files for the tropical cyclone tracks used in this study. I am grateful for Ms. May Toe Aung Myint, Department of Agriculture, Labutta Township, Ayeyarwady Province, Myanmar for providing valuable local information on rice varieties planted in the Delta. I would also like to thank Editage (www.editage.com) for their English language editing services. The comments of three reviewers strengthened the final manuscript.

Funding This study was funded by the Ministry of Agriculture, Forestry and Fisheries of Japan.

\section{Compliance with ethical standards}

Conflict of interest There are no conflicts of interest to declare.

Open Access This article is licensed under a Creative Commons Attribution 4.0 International License, which permits use, sharing, adaptation, distribution and reproduction in any medium or format, as long as you give appropriate credit to the original author(s) and the source, provide a link to the Creative Commons licence, and indicate if changes were made. The images or other third party material in this article are included in the article's Creative Commons licence, unless indicated otherwise in a credit line to the material. If material is not included in the article's Creative Commons licence and your intended use is not permitted by statutory regulation or exceeds the permitted use, you will need to obtain permission directly from the copyright holder. To view a copy of this licence, visit http://creativecommons.org/licenses/by/4.0/.

\section{References}

Al Ruheili A, Radke J (2020) Visualization of 2002 storm surge along the coast of Dhofar, case study of Oman. Environ Dev Sustain 22(1):501-517. https://doi.org/10.1007/s10668-018-0186-z

ASEAN Food Security Information System (AFSIS) (2018) ASEAN Agricultural Commodity Outlook No.20 June 2018. Bangkok: AFSIS Secretariat, Office of Agricultural Economics (OAE), Ministry of Agriculture and Cooperatives.

Balaguru K, Taraphdar S, Leung LR, Foltz GR (2014) Increase in the intensity of postmonsoon Bay of Bengal tropical cyclones. Geophys Res Lett 41(10):3594-3601. https://doi.org/10.1002/2014G L060197

Department of Agriculture Labutta Township (2020) Field statistics.

Dong L, McPhaden MJ (2016) Interhemispheric SST gradient trends in the Indian Ocean prior to and during the recent global warming hiatus. J Clim 29:9077-9095. https://doi.org/10.1175/ jcli-d-16-0130.1

Dube SK, Jain I, Rao AD, Murty TS (2009) Storm surge modelling for the Bay of Bengal and Arabian Sea. Nat Hazards 51(1):3-27. https ://doi.org/10.1007/s11069-009-9397-9 
Eckstein D, Künzel V, Schäfer L (2017) Global climate risk index 2018. Germanwatch e.V, Berlin

England MH, McGregor S, Spence P, Meehl GA, Timmermann A, Cai WJ et al (2014) Recent intensification of wind-driven circulation in the Pacific and the ongoing warming hiatus. Nature Clim Change 4(3):222-227. https://doi.org/10.1038/nclimate2016

FAO (2019) Handbook on climate smart agriculture in Myanmar. Food and Agriculture Organization of the United Nations and AVSI Foundation, Nay Pyi Taw

Fritz HM, Blount CD, Thwin S, Thu MK, Chan N (2009) Cyclone Nargis storm surge in Myanmar. Nat Geosci 2(7):448-449. https ://doi.org/10.1038/ngeo558

Getis A, Ord JK (1992) The analysis of spatial association by use of distance statistics. Geogr Anal 24(3):189-206

IPCC (2013) Summary for Policymakers. In: Stocker TF, Qin D, Plattner G-K, Tignor M, Allen SK, Boschung J et al (eds) Climate Change 2013: The Physical Science Basis. Contribution of Working Group I to the Fifth Assessment Report of the Intergovernmental Panel on Climate Change. Cambridge University Press, Cambridge, United Kingdom and New York, NY, USA

IPCC (2014) Asia. In Climate Change 2014: Impacts, adaptation and vulnerability. Part B: Regional aspects. Contribution of Working Group II to the Fifth Assessment Report of the Intergovernmental Panel on Climate Change, pp 1327-1370. Cambridge University Press, Cambridge, United Kingdom and New York, NY, USA

Islam MA, Hossain MS, Murshed S (2015) Assessment of coastal vulnerability due to sea level change at Bhola Island, Bangladesh: using geospatial techniques. J Indian Soc Remote Sens 43(3):625637. https://doi.org/10.1007/s12524-014-0426-0

Islam T, Peterson R (2009) Climatology of landfalling tropical cyclones in Bangladesh 1877-2003. Nat Hazards 48(1):115-135. https:// doi.org/10.1007/s11069-008-9252-4

Jain I, Chittibabu P, Agnihotri N, Dube SK, Sinha PC, Rao AD (2006) Simulation of storm surges along Myanmar coast using a location specific numerical model. Nat Hazards 39(1):71-82. https://doi. org/10.1007/s11069-005-3176-z

Knapp KR, Kruk MC, Levinson DH, Diamond HJ, Neumann CJ (2010) The International Best Track Archive for Climate Stewardship (IBTrACS) unifying tropical cyclone data. Bull Am Meteorol Soc 91(3):363-376. https://doi.org/10.1175/2009bams2755.1

Knapp KR, Diamond HJ, Kossin JP, Kruk MC, Schreck CJ (2018) International Best Track Archive for Climate Stewardship (IBTrACS) Project, Version 4.0. https://doi.org/10.25921/82ty-9e16. Accessed 25 May 2020.

Knutson TR, McBride JL, Chan J, Emanuel K, Holland G, Landsea $\mathrm{C}$ et al (2010) Tropical cyclones and climate change. Nat Geosci 3(3):157-163. https://doi.org/10.1038/ngeo779

Kossin JP, Emanuel KA, Vecchi GA (2014) The poleward migration of the location of tropical cyclone maximum intensity. Nature 509(7500):349-352. https://doi.org/10.1038/nature13278

Kossin JP, Knapp KR, Olander TL, Velden CS (2020) Global increase in major tropical cyclone exceedance probability over the past four decades. Proc Natl Acad Sci. https://doi.org/10.1073/pnas.19208 49117

Krishna KM (2009) Intensifying tropical cyclones over the North Indian Ocean during summer monsoon-Global warming. Global Planet Change 65(1-2):12-16. https://doi.org/10.1016/j.glopl acha.2008.10.007

Kumar PKD, Paul YS, Muraleedharan KR, Murty VSN, Preenu PN (2016) Comparison of long-term variability of sea surface temperature in the Arabian Sea and Bay of Bengal. Reg Stud Mar Sci 3:67-75. https://doi.org/10.1016/j.rsma.2015.05.004

Lenssen NJL, Schmidt GA, Hansen JE, Menne MJ, Persin A, Ruedy $\mathrm{R}$, Zyss D (2019) Improvements in the GISTEMP uncertainty model. J Geophys Res: Atmos 124:6307-6326. https://doi. org/10.1029/2018jd029522
Liao EH, Lu WF, Yan XH, Jiang YW, Kidwell A (2015) The coastal ocean response to the global warming acceleration and hiatus. Sci Rep 5:10. https://doi.org/10.1038/srep16630

Myanmar Government (2009) Hazard profile of Myanmar: Asian Disaster Preparedness Center (ADPC).

Myanmar Government (2012) Myanmar's National Adaptation Programme of Action (NAPA) to Climate Change. Nay Pyi Taw: Department of Meteorology and Hydrology and Ministry of Transport, Union of Myanmar.

Myanmar Government (2013) Myanmar Agriculture in a Glance. Nay Pyi Taw: Ministry of Agriculture and Irrigation (MoAI).

Myanmar Government (2015) Myanmar Statistical Yearbook 2015. Ministry of National Planning and Economics Development, Nay Pyi Taw

Needham HF, Keim BD, Sathiaraj D (2015) A review of tropical cyclone-generated storm surges: global data sources, observations, and impacts. Rev Geophys 53(2):545-591. https://doi. org/10.1002/2014rg000477

Reynolds RW, Rayner NA, Smith TM, Stokes DC, Wang WQ (2002) An improved in situ and satellite SST analysis for climate. J Clim 15(13):1609-1625. https://doi.org/10.1175/15200442(2002)015\%3c1609:aiisas\%3e2.0.co;2

Singh OP (2007) Long-term trends in the frequency of severe cyclones of Bay of Bengal: observations and simulations. Mausam 58(1):59-66

Singh OP, Khan TMA, Rahman MS (2000) Changes in the frequency of tropical cyclones over the North Indian Ocean. Meteorol Atmos Phys 75(1-2):11-20. https://doi.org/10.1007/s007030070011

Singh OP, Khan TMA, Rahman S (2001) Has the frequency of intense tropical cyclones increased in the north Indian Ocean? Curr Sci 80(4):575-580

Stone R (2009) Myanmar one year after a devastating cyclone: a bitter harvest. Science 324(5928):715-715

Islam SMT, Chik Z (2011) Disaster in Bangladesh and management with advanced information system. Disaster Prev Manag 20(5):521-530. https://doi.org/10.1108/09653561111178952

Tasnim KM, Shibayama T, Esteban M, Takagi H, Ohira K, Nakamura R (2015) Field observation and numerical simulation of past and future storm surges in the Bay of Bengal: case study of Cyclone Nargis. Nat Hazards 75(2):1619-1647. https://doi.org/10.1007/ s11069-014-1387-x

van Driel WF, Nauta TA (2015) Vulnerability and resilience assessment of the Ayeyarwady Delta in Myanmar. Full assessment report. Delta Alliance Report No. 10. Global Water Partnership and Delta Alliance, pp 148.

Walsh J (2012) Cyclones. In: Philander SG (ed) Encyclopedia of Global Warming and Climate Change, 2nd edn. SAGE Publications, Thousand Oaks, California, p 1161

Wang S-Y, Buckley BM, Yoon J-H, Fosu B (2013) Intensification of premonsoon tropical cyclones in the Bay of Bengal and its impacts on Myanmar. J Geophys Res-Atmos 118(10):4373-4384. https:// doi.org/10.1002/jgrd.50396

Webb EL, Jachowski NRA, Phelps J, Friess DA, Than MM, Ziegler AD (2014) Deforestation in the Ayeyarwady Delta and the conservation implications of an internationally-engaged Myanmar. Global Environ Change 24:321-333. https://doi.org/10.1016/j. gloenvcha.2013.10.007

Webster PJ, Holland GJ, Curry JA, Chang HR (2005) Changes in tropical cyclone number, duration, and intensity in a warming environment. Science 309(5742):1844-1846. https://doi.org/10.1126/ science. 1116448

Yamada H, Moteki Q, Yoshizaki M (2010) The unusual track and rapid intensification of Cyclone Nargis in 2008 under a characteristic environmental flow over the Bay of Bengal. J Meteorol Soc Jpn 88(3):437-453. https://doi.org/10.2151/jmsj.2010-311 